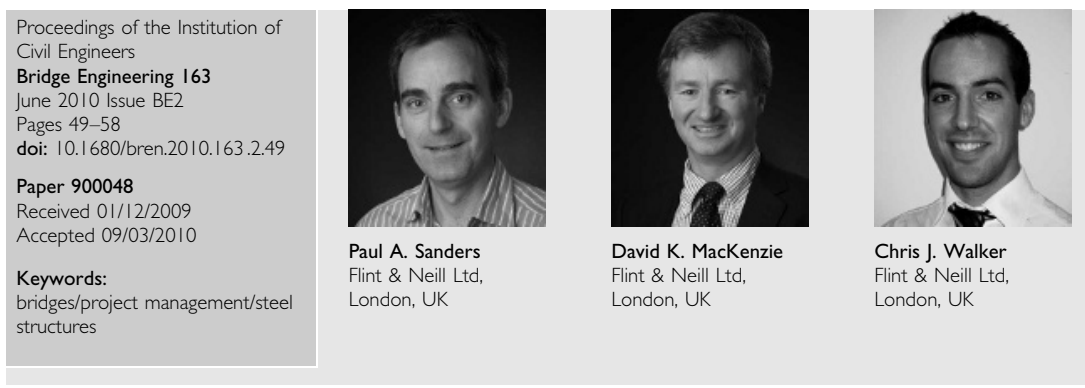

\title{
Design and construction of the Fabian Way bridge superstructure
}

P. A. Sanders ACGI, CEng, MICE, D. K. MacKenzie MS, CEng, FIStructe, MASCE, MHIKE and C. J. Walker MA(Cantab), MEng, MSc, DIC

The Fabian Way Bridge crosses a dual carriageway in Swansea and forms part of a local express bus route. The bridge is a $71 \mathrm{~m}$ long, heavily skewed cable stayed structure with a single central spine beam. Cantilevers extending either side of the central spine beam support twin orthotropic decks that carry vehicle and pedestrian traffic. The deck is supported by a slender inclined mast with an unusual open cross-section. The superstructure design was developed in close collaboration with the end client, main contractor and steelwork sub-contractor as an alternative to the client's original design, and maximises offsite prefabrication and buildability while achieving a graceful yet striking new landmark. The paper presents an interesting case study describing the reasons for the selection of an all-steel deck as the preferred solution, along with special aspects of the detailed design including the buckling analysis of the

mast. The paper also describes the positive impact on urban regeneration, as well as the construction of the bridge. Ways in which a very tight design and construction programme was achieved are also described, together with issues affecting long-term maintenance of the bridge.

\section{INTRODUCTION}

Swansea is a city with a population of approximately 250000 people located at the western end of the industrial zone stretching across South Wales. The client, City and County of Swansea, is committed to developing efficient and sustainable passenger transport systems to provide access to the city centre from the major approach roads. Part of this strategy includes the creation of out-of-town 'park and ride' facilities with dedicated express bus routes to the city centre. The eastern approach to Swansea is served by the Fabian Way park-and-ride facility, which has been in operation for a number of years. The associated express bus route had been partly constructed and the client had identified the need to provide a new bridge across the A483 Fabian Way, which forms the main approach to the city from the east.

The bridge is prominently located and an opportunity was identified to provide a landmark structure. Projects such as the Gateshead Millennium bridge have shown that landmark bridge designs attract interest and investment to the surrounding area and effectively provide a net cost benefit after consideration of the construction costs. The same model was shown to work on the nearby Port Tawe development where a bridge, also designed by Flint $\&$ Neill, has acted as a catalyst for the development and contributed significantly towards its success (Sanders and Firth, 2005).

This paper describes the design of the superstructure and the reasons for the selection of steel as the preferred material. It also describes key aspects of the bridge erection and stay stressing procedures, and how the design and detailing were developed to suit the contractor's preferred method of working and accelerate construction.

\section{BACKGROUND}

The client's design brief for the bridge was to provide an iconic and landmark structure carrying a single lane carriageway and a cycleway and pedestrian route across the A483. The bridge is located on the site of a former railway bridge demolished in 2003. Substructure design was carried out by the client's inhouse design team. The concept design of the superstructure was procured externally through an invited design competition. The selected concept design was submitted by Parsons Brinkerhoff Ltd in conjunction with Studio Bednarski of London.

The competition stage scheme had a $71 \mathrm{~m}$ span deck on a plan skew of $65^{\circ}$ to follow the available corridor. The deck was suspended from stays attached to a mast inclined forwards by $22^{\circ}$ and anchored by two sets of back stays twisted into a warped plane giving the bridge a graceful yet striking appearance. The original deck design was based on traditional steel-concrete composite construction. The general arrangement of the bridge is shown in Figure 1.

A contract for construction of the bridge was awarded to Alun Griffiths Ltd for a final outturn value of $£ 4.2$ million (approximately $€ 5.5$ million) in August 2006. Rowecord Engineering Ltd was appointed as specialist steelwork subcontractor. Shortly after the award of the contract Flint \& Neill was appointed to prepare alternative designs for the superstructure. The initial brief was to examine steel deck alternatives following a review of the buildability of the original steelconcrete composite deck undertaken by the contractor. This brief was subsequently extended to include the design of the entire superstructure including redesign of the mast and stay systems. 


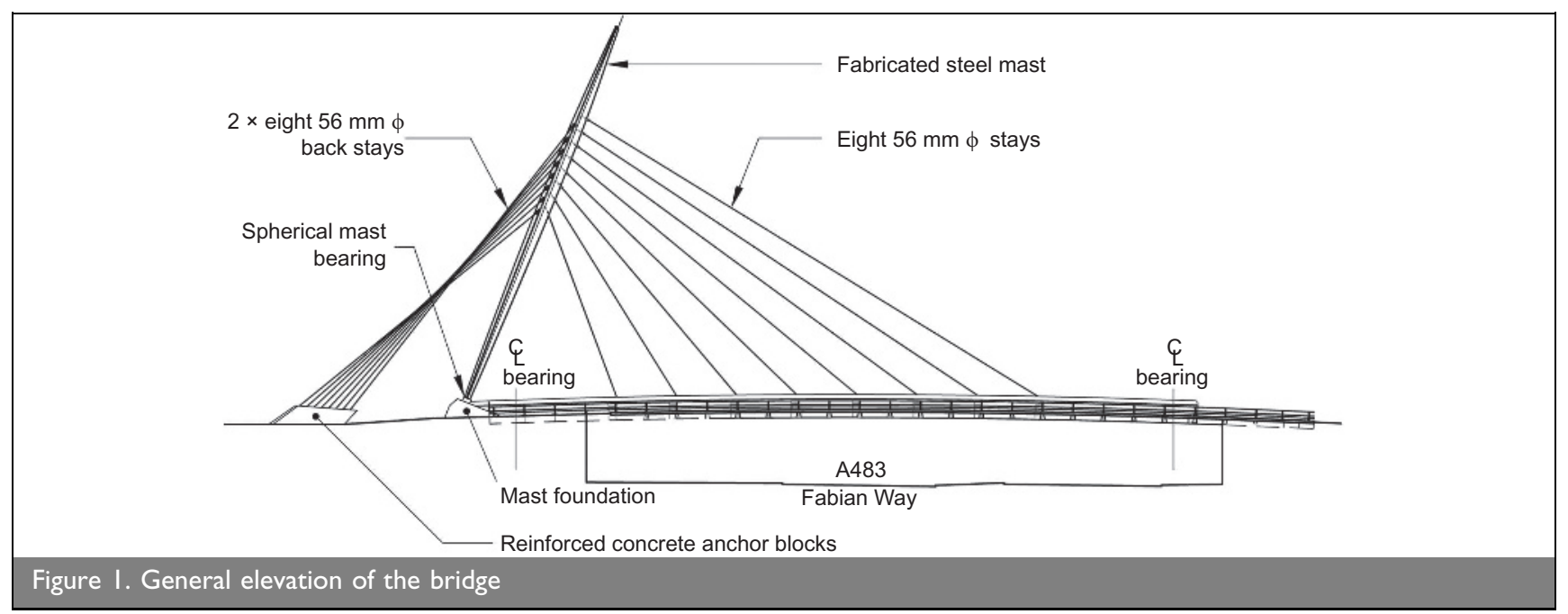

\section{ALTERNATIVE DECK DESIGN}

The deck consists of a single central spine beam with cantilevers on either side supporting separate orthotropic steel vehicle and pedestrian/cycle decks (see Figure 2). The central spine beam is suspended from eight front stays and two sets of eight back stays and is capped with an architectural cowling. The gap between the spine beam and deck plates is in-filled with stainless steel mesh.

Steel decks are not normally economical for structures of this span and type. However, for this project an all-steel vehicle deck offered a number of direct and indirect cost and sustainability benefits when compared with the original composite design

(a) It maximised off-site prefabrication and minimised on-site work over the live carriageways of the A483. The A483 is a busy arterial highway that could not be fully closed during weekday daytime periods.

(b) It eliminated the need for concreting over a live carriageway and therefore significantly reduced the number of lane closures required and the amount of work carried out at height, with obvious safety benefits.

(c) The lighter steel deck significantly reduced the axial load on the mast and enabled the mast cross-section to be simplified. This provided benefits in terms of reductions in the overall weight of steel, fabrication costs and long-term maintenance costs. The ultimate limit state (ULS) axial force at the base of the mast was reduced from $32000 \mathrm{kN}$ to $16000 \mathrm{kN}$.

(d) It allowed the stay size to be reduced from a mix of 70, 80 and $90 \mathrm{~mm}$ diameter strands to $56 \mathrm{~mm}$ diameter strands, and resulted in a corresponding reduction in stay preloads and therefore the size of the jacking equipment required. (e) It resulted in lower foundation loads beneath the mast, which in turn allowed pile lengths to be reduced. It also reduced the uplift forces on the back stay anchor blocks, again allowing pile lengths to be reduced.

$(f)$ The spacing of cross-girders was increased from $2.6 \mathrm{~m}$ to $3.3 \mathrm{~m}$, thus simplifying the design of the spine beam.

The design changes saved money, which the client spent enhancing other aspects of the design including the aesthetics of the bridge. A bespoke pedestrian parapet and architectural lighting scheme were introduced and the cross-section geometry was improved by tapering the depths of the cantilevers.

The steel vehicle deck consists of a $16 \mathrm{~mm}$ thick plate longitudinally stiffened with $220 \mathrm{~mm}$ deep bulb flats at $300 \mathrm{~mm}$ centres (see Figure 3). For orthotropic steel decks, bulb flats are both cheaper and less demanding on the fabricator than more commonly specified trough stiffeners. The quality of the part penetration weld between the web of trough stiffeners and the deck plate fundamentally affects the fatigue performance of an orthotropic deck plate. To achieve good quality part penetration welds with trough stiffeners generally requires specialist automatic welding beds and extremely high workmanship standards. Generally, when trough stiffeners are used, an effective weld throat thickness of approximately $80 \%$ of the trough wall thickness is preferred. Careful control of the welding process is required to prevent the weld, which does not include a backing plate, blowing through. Furthermore, like any single-sided weld there is effectively an inbuilt defect at the weld toe where the trough is in contact with the underside of the deck plate. At this point, tensile stresses that arise through transverse bending of the trough wall under the action of local wheel loads tend to result in

Figure 2. Alternative steel deck cross-section (dimensions in $\mathrm{mm}$ ) 


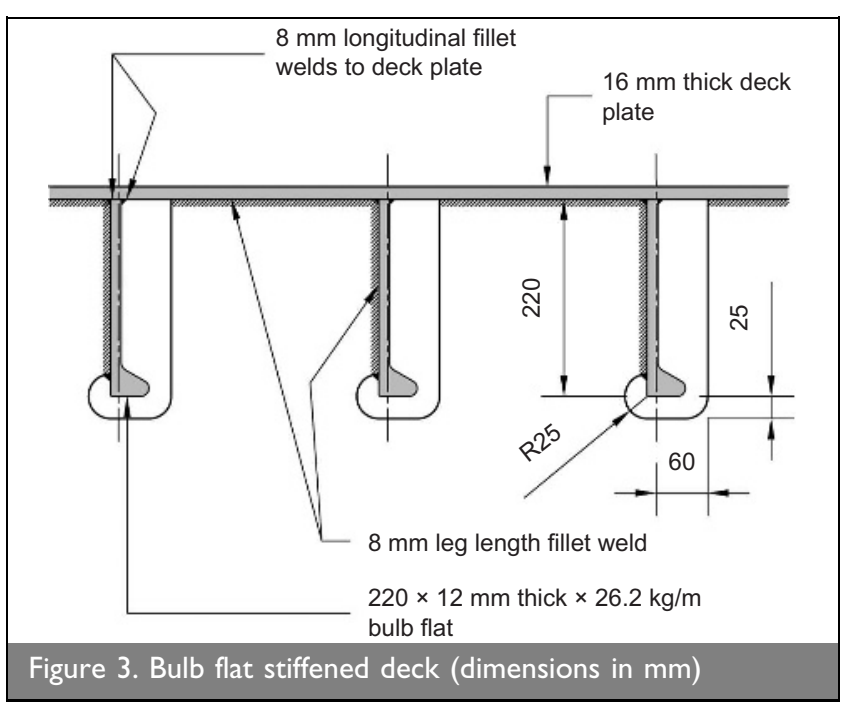

a stress concentration and therefore an inherently poor fatigue detail, something that is not present in a double-sided fillet weld. These two effects are substantially mitigated by ensuring that the trough is closely fitted to the underside of the deck plate during assembly. Weld shrinkage appears to offer further benefit by precompressing the weld, therefore reducing the effect of any transient tensile stresses. However, the equipment and expertise required to address these issues is available to very few fabricators and in practice is therefore not readily mobilised, nor economic to utilise for small-scale projects.

With a double-sided fillet weld at the deck-stiffener connection, bulb flats are much easier for a fabricator to use, resulting in inherent cost savings. Furthermore, at $300 \mathrm{~mm}$ transverse centres the longitudinal bending stiffness of the bulb flat deck is $17800 \mathrm{~cm}^{4}$ per metre width, which is approximately 5\% more than a typical $250 \mathrm{~mm}$ deep trough-stiffened deck. However, the disadvantage is that open stiffeners do not reduce transverse bending stresses in the deck plate under local wheel loads as effectively as torsionally stiff closed stiffeners do. These local stresses tend to govern the design as they determine the fatigue resistance of such decks.

After balancing the reduced fatigue performance against the saving in fabrication costs, bulb flat stiffeners were selected. It is worth noting that, although less common, bulb flats have an established track record on highway bridges. Each bulb flat is connected to the deck plate by a continuous double-sided fillet weld.

Deck details were based on the guidance given in annexe $\mathrm{C}$ of Eurocode 3 part 2 (BSI, 2006). Detailed fatigue checks were made on typical details using BS 5400 part 10 (BSI, 1980). Fatigue classifications were based on published literature including Eurocode 3; these are summarised in Table 1. Stresses were derived from a detailed finite-element model (see
Figure 4). Previous studies indicated that a $14 \mathrm{~mm}$ thick deck plate combined with a $40 \mathrm{~mm}$ flexible surfacing system would perform satisfactorily. However, in line with the guidelines given in Eurocode 3 (BSI, 2006) a $16 \mathrm{~mm}$ thick deck plate was adopted. Longitudinal butt welds in the deck plate were positioned approximately one-third of the way between stiffeners in a location where transverse bending stresses in the deck plate are lower. Furthermore, longitudinal butt welds were located in positions away from the wheel tracks.

It was not possible to observe the guidelines given in Eurocode 3 (BSI, 2006) with regard to the preferred depth of the cross-girder web resulting in a critical detail around the cut-outs for the bulb flats in cross-girder webs. The shallow depth of the cross-girder results in significant vierendeel bending around the stiffener cut-outs towards the root of the cantilever where the shear force is greatest. In order to achieve a satisfactory fatigue life the cutout was ground to achieve a class ' $\mathrm{C}$ ' fatigue detail. It was found that the in-plane vierendeel effect resulted in stresses several times greater than the out-of-plane web bending effects that arise from continuity with the deck plate.

Axial load generated in the bridge deck as a result of the stay inclination is taken through a thrust bearing at the end of the spine beam. Longitudinally guided bearings are provided beneath the central spine beam at both ends and free sliding bearings beneath the outer ends of the trimmer beams that provide support to the skewed portion of the deck (see Figure 14 in Section 6). The skew, coupled with the unequal weights of the vehicle and pedestrian decks, results in high uplift forces on the trimmer beam bearing at the obtuse corner of the pedestrian deck. This was an unavoidable feature of the skewed layout and resulted in an uplift bearing with a ULS capacity of approximately $1250 \mathrm{kN}$. This in turn necessitated a fabricated steel hold-down system anchored into the abutment.

\section{STAY DESIGN}

The stays are $56 \mathrm{~mm}$ diameter locked-coil cables supplied by Redaelli-Tecna Spa of Italy. At the mast the stays are anchored using clevis and pin assemblies. When pricing stay options, locked-coil cables were found to be no more expensive than spiral strand cables and, although they are more difficult to handle in terms of coiling and uncoiling, they offer improved durability as a result of the interlocking nature of the ' $\mathrm{z}$ '-shaped external wires. Stressing and adjustment of the stay lengths is made at the lower end of the stays (see Figures 5 and 6). Front stays are anchored inside the spine beam by means of threaded cylindrical sockets. Back stays are anchored at the anchor blocks by means of clevis and pin assemblies and turnbuckles are provided for length adjustment.

A detailed study was undertaken to assess the susceptibility of stays to wind-induced vibrations, including vortex shedding,

\begin{tabular}{|lll|}
\hline Weld detail & Fatigue class to BS 5400-10 & Reference stress \\
\hline $\begin{array}{l}\text { Deck plate to web of bulb flat } \\
\text { Web of transverse girder at web cut-out }\end{array}$ & D & Underside of deck plate $15 \mathrm{~mm}$ from toe of weld \\
for bulb flat & C & Web plate at $15 \mathrm{~mm}$ from toe of weld \\
& Along perimeter of cut-out for bulb flat \\
\hline Table I. Summary of fatigue classifications for deck design & \\
\hline
\end{tabular}




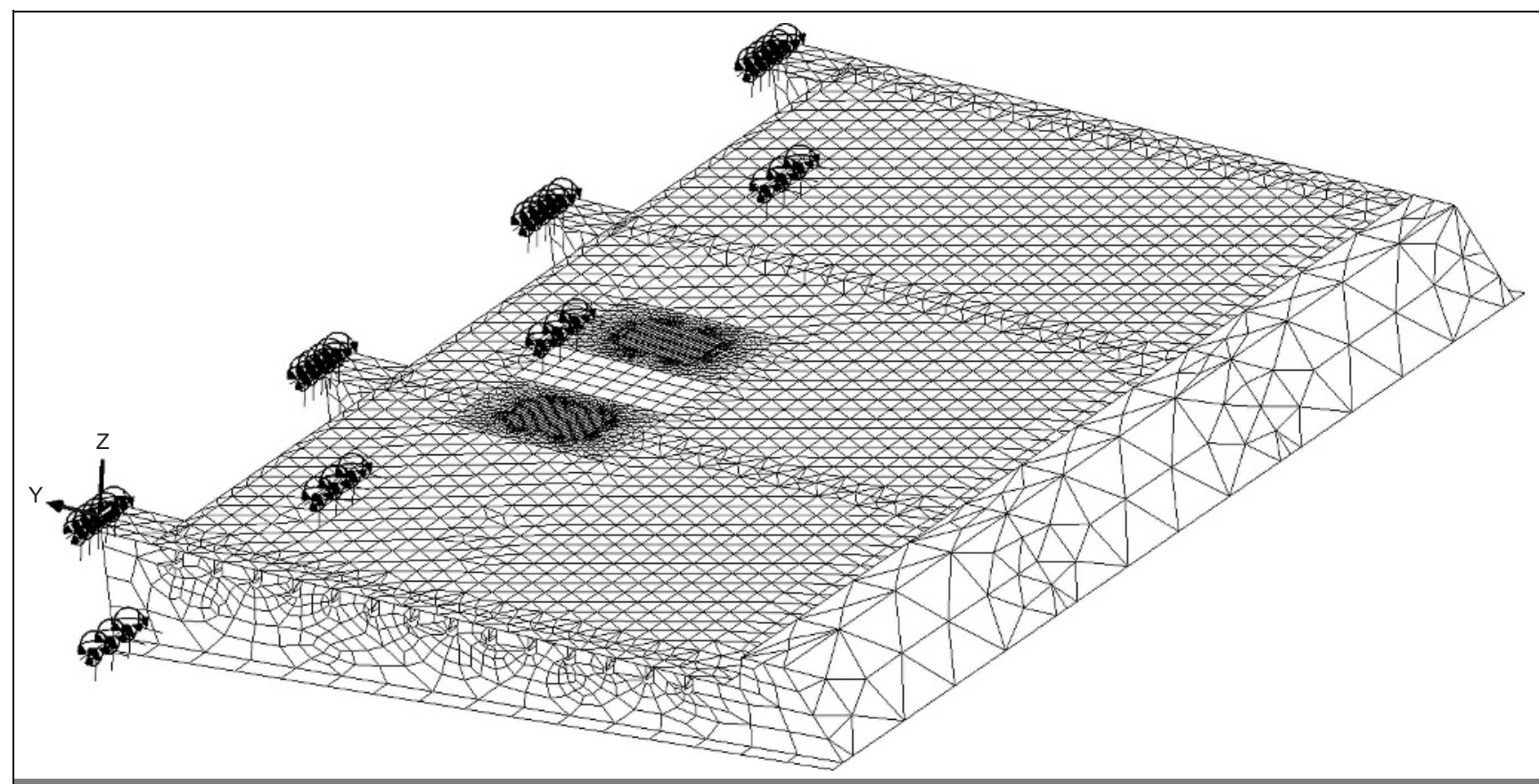

Figure 4. Local finite-element model of deck

buffeting and wind-rain oscillations. This concluded that the risk of vibration was low and the decision was taken to omit any form of mitigation, but with provision made to retro-fit damping devices should unacceptable oscillations be observed in service. This was most likely for the twisted back stays, which pass within $30 \mathrm{~mm}$ of one another where they cross and thus even small levels of vibration were unacceptable. The risk of

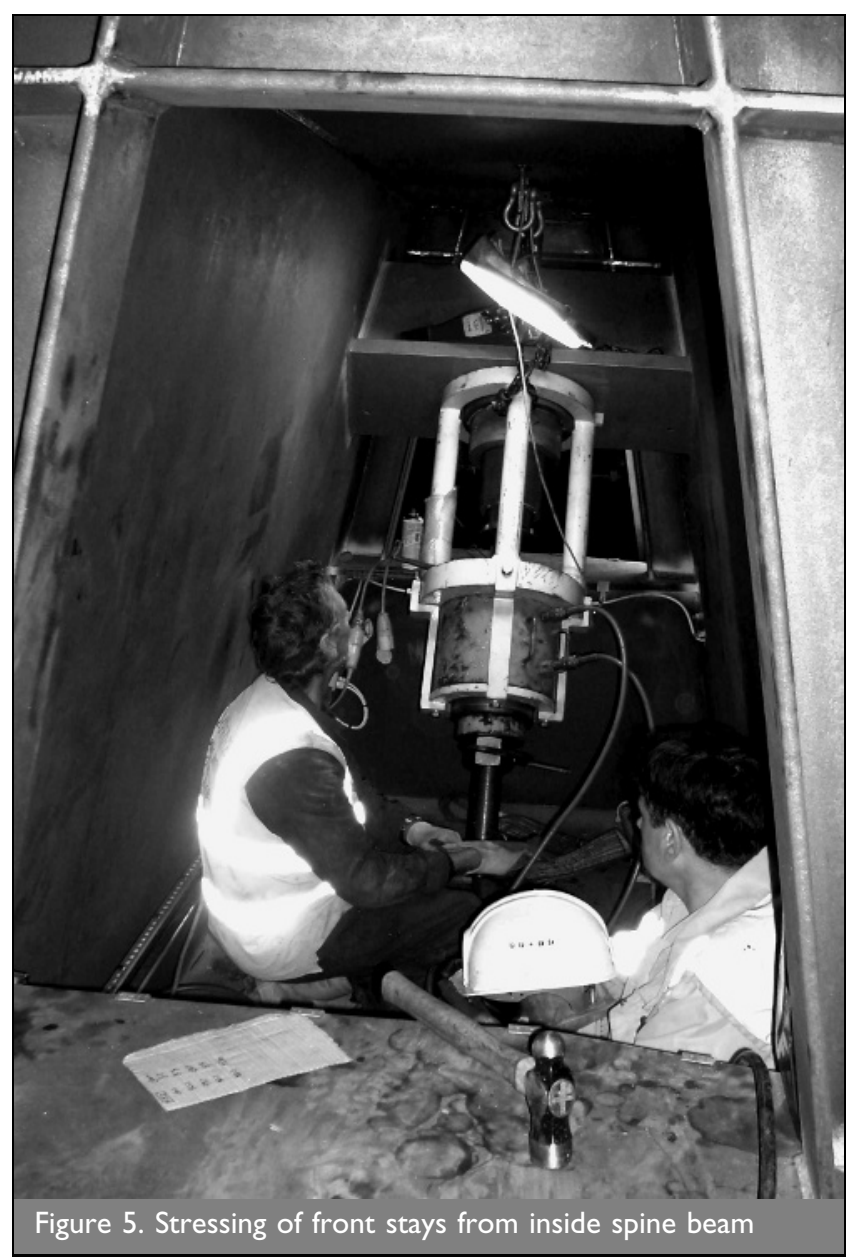

wind-rain-induced vibration was increased by the use of locked-coil cables, which have a smooth exterior surface and thus offer no resistance to the formation of a rainwater rivulet, which can lead to destabilising drag forces on the cable section. Subsequent inspections revealed some evidence of stays coming into contact and therefore short lengths of a sacrificial wrapping system have been proposed to protect the stays.

\section{MAST DESIGN}

Details of the mast are shown in Figure 7. Architectural considerations were behind the mast design. A series of flat

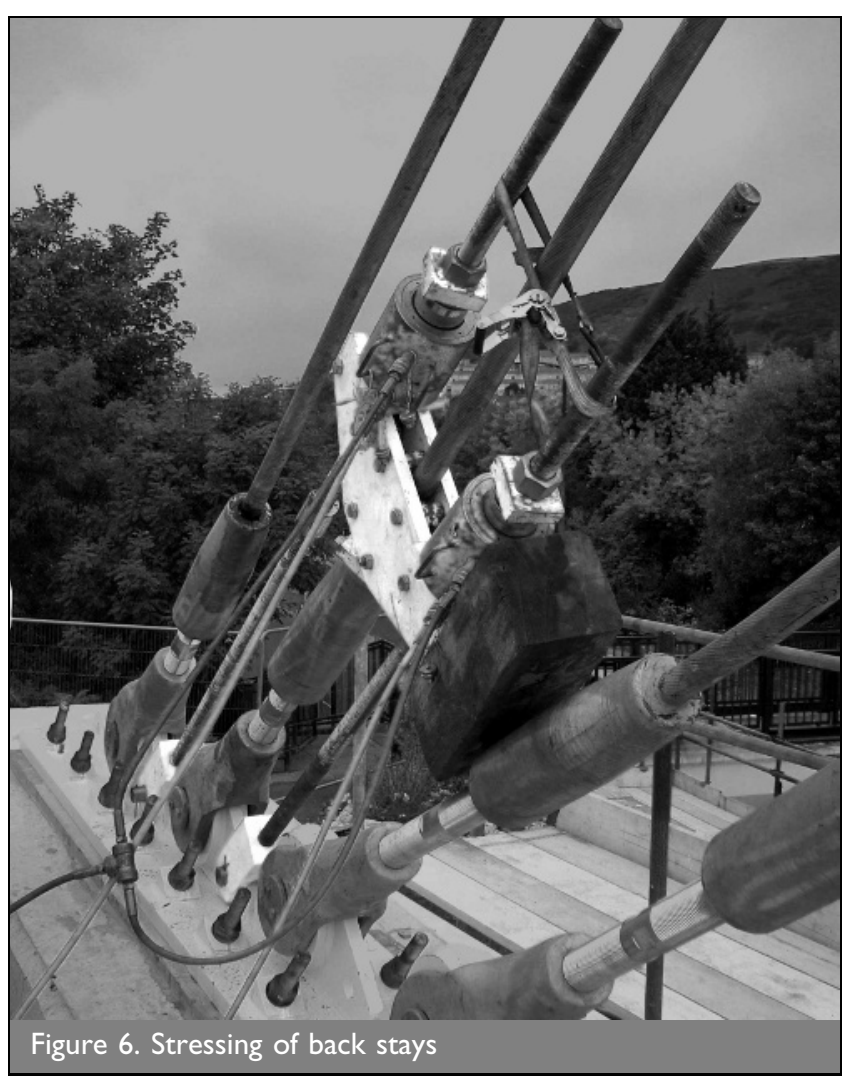




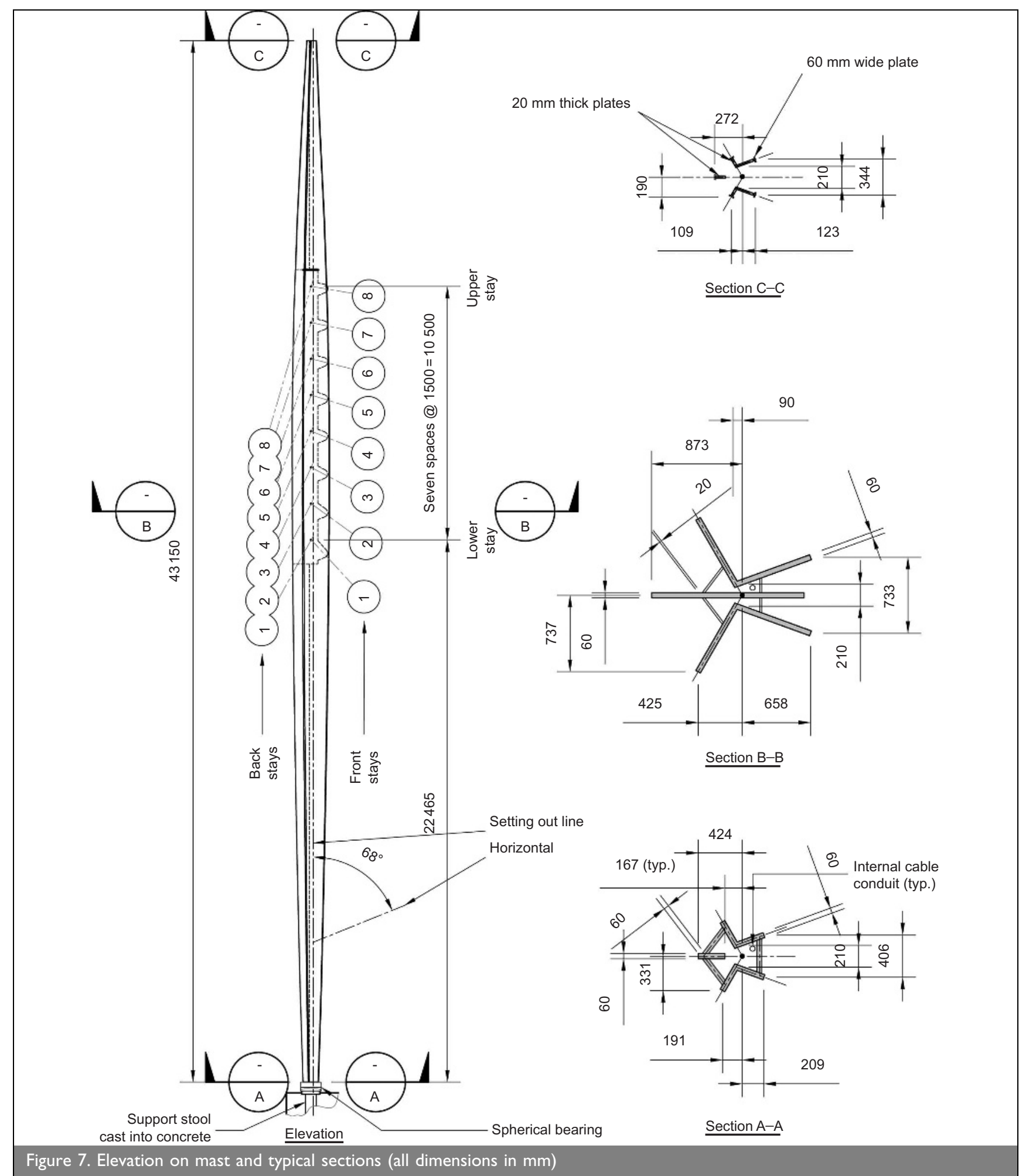

surfaces is created, each of which catches the light, emphasising its geometry. A typical stay anchorage arrangement at the mast is shown in Figure 8. The main longitudinal plates are $60 \mathrm{~mm}$ thick up to the top of the stay anchorage zone. The $43 \mathrm{~m}$ long cigar-shaped mast is $1.53 \mathrm{~m}$ wide at its widest point and appears to be very slender (see Figures 9 and 10).

A torsionally stiff closed section is provided within the core of the mast from the stay anchorage zone to the base of the mast, where a $750 \mathrm{~mm}$ diameter bespoke spherical bearing is provided. The contact surfaces are nickel-plated and coated with marine grease. As the mast bearing cannot be replaced without substantially dismantling the bridge, the entire design accounted for the effect of the contact faces locking and a moment connection developing at the base of the mast.

The open cross-section, complex restraint conditions provided by the stay system and architectural desire to maximise overall slenderness dictated that the global stability of the mast at ULS be assessed from first principles. An initial imperfection was built into the global finite-element model and a largedisplacement analysis carried out using ULS load combinations designed to maximise axial forces or bending moments in the mast. The magnitude of the initial imperfection was chosen to be 


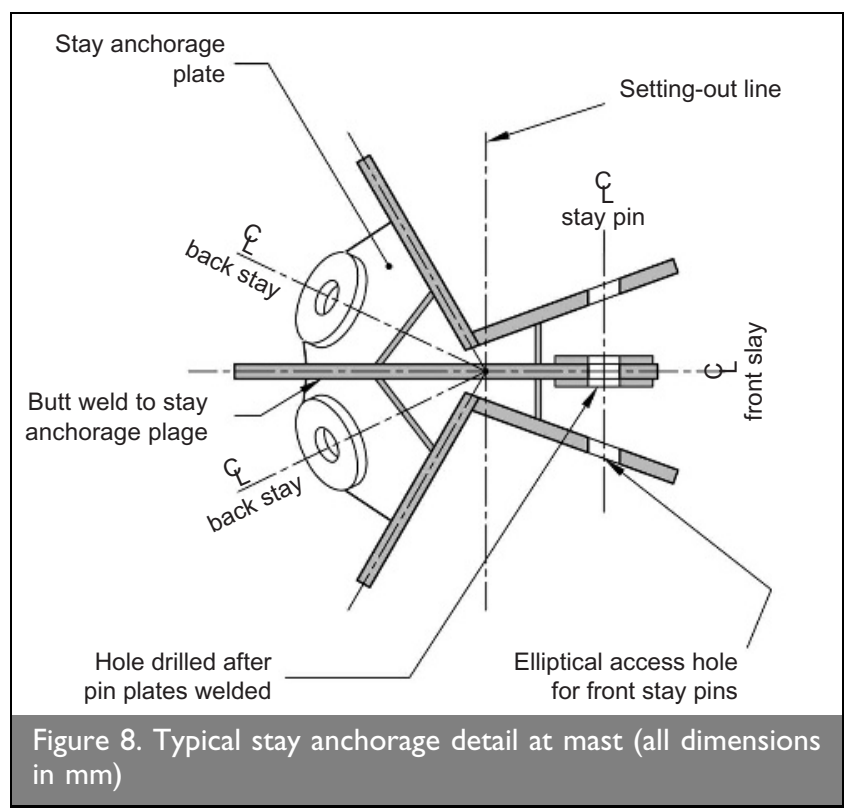

twice the fabrication tolerance specified by BS 5400-6 (BSI, 1999) in order to provide some allowance for the early onset of yield and loss of stiffness caused by residual stresses. An incremental series of load cases was then run in which the total ULS applied loads were multiplied by an increasing factor, $F$.

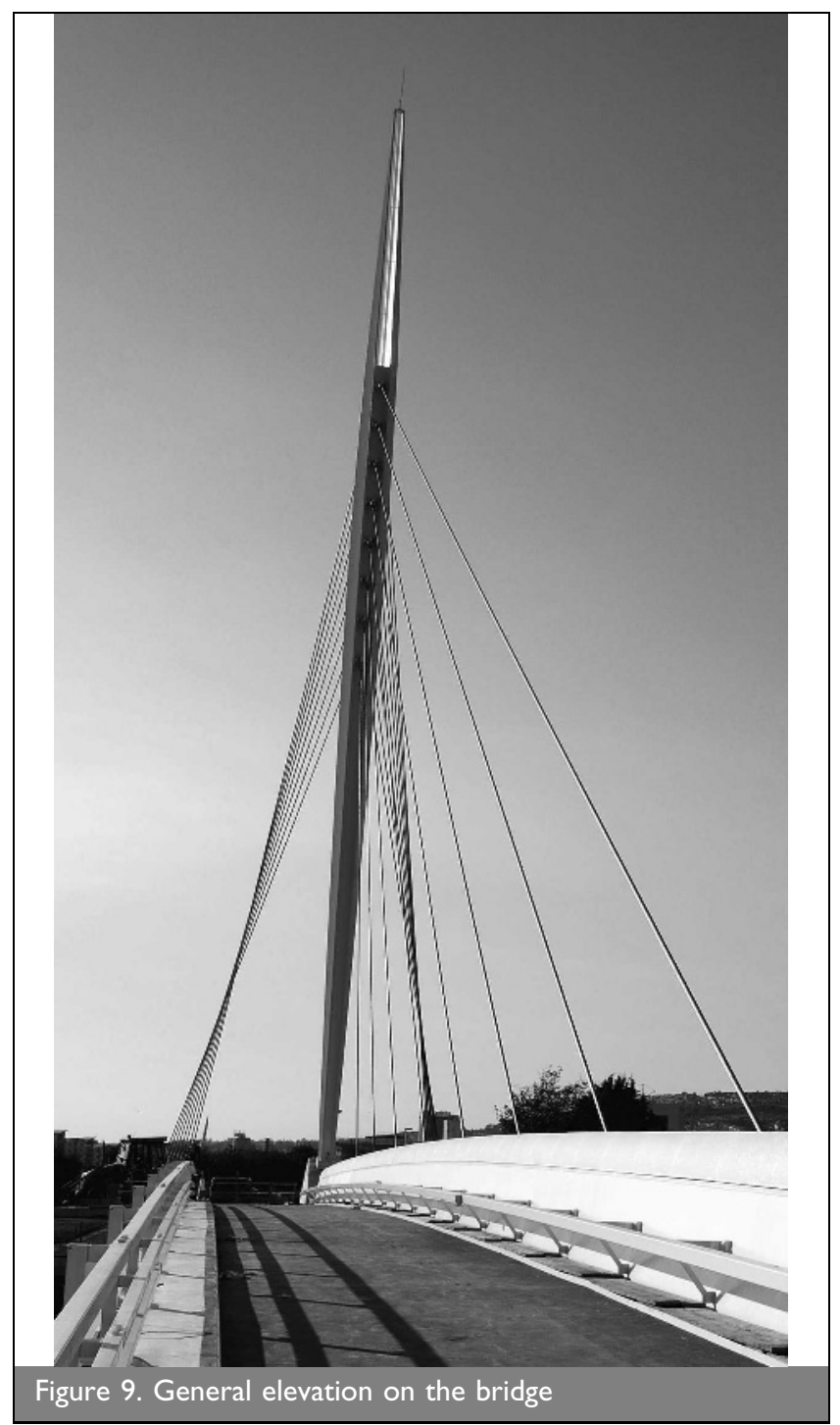

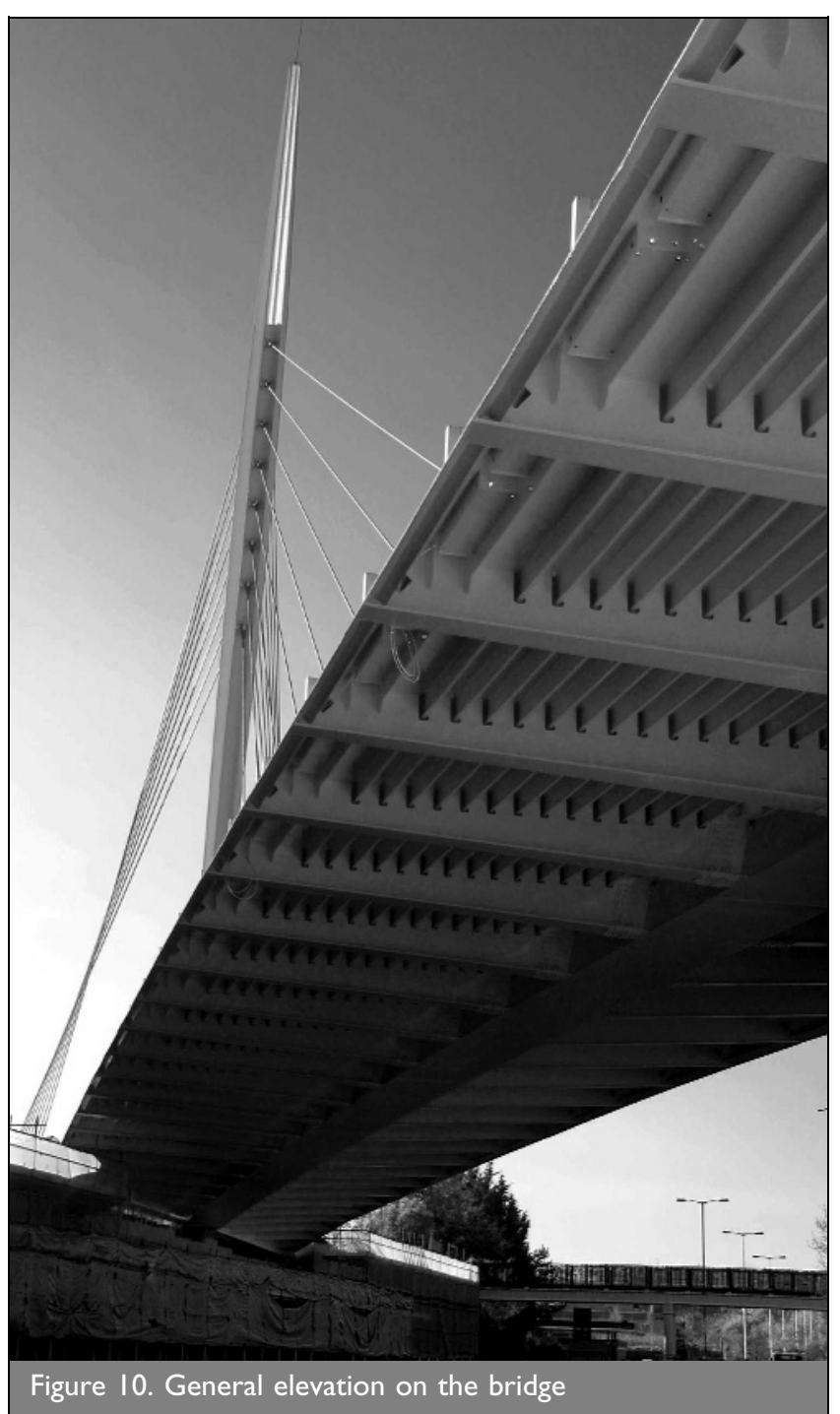

Failure was assumed to occur when the extreme fibre of any plate forming the mast cross-section reached the allowable outstand stress given in BS5400-3 (BSI, 2000); any reserve of capacity after yield was neglected. For each load case the utilisation ratio $F / U$ was calculated where $U$ is the ratio between the maximum longitudinal stress anywhere in the mast and the allowable. A typical plot of $F / U$ against $F$ is shown in Figure 11. The line $F=F / U$ is also shown and where each curve intersects this, the utilisation is equal to unity and the value of $F$ indicates the overall factor of safety on the total ULS applied loads.

Interpolating within these results, $60 \mathrm{~mm}$ thick longitudinal plates in the mast provided a factor of safety of 1.95 on the total ULS loads, which was deemed to provide a sufficiently robust design. This result was verified by calculating static eigenvalues from which the mast's elastic critical axial force and thus the effective wavelength of buckling could be calculated. This effective length was used to derive a design capacity based on strut buckling curves given in BS 5400-3 (BSI, 2000). This proved to be a much more conservative approach, indicating that the capacity was only marginally greater than the applied ULS load.

The large-displacement analysis assumed an initial imperfection in the mast with maximum amplitude of $80 \mathrm{~mm}$, in order to ensure that the design was not unduly sensitive to fabrication 


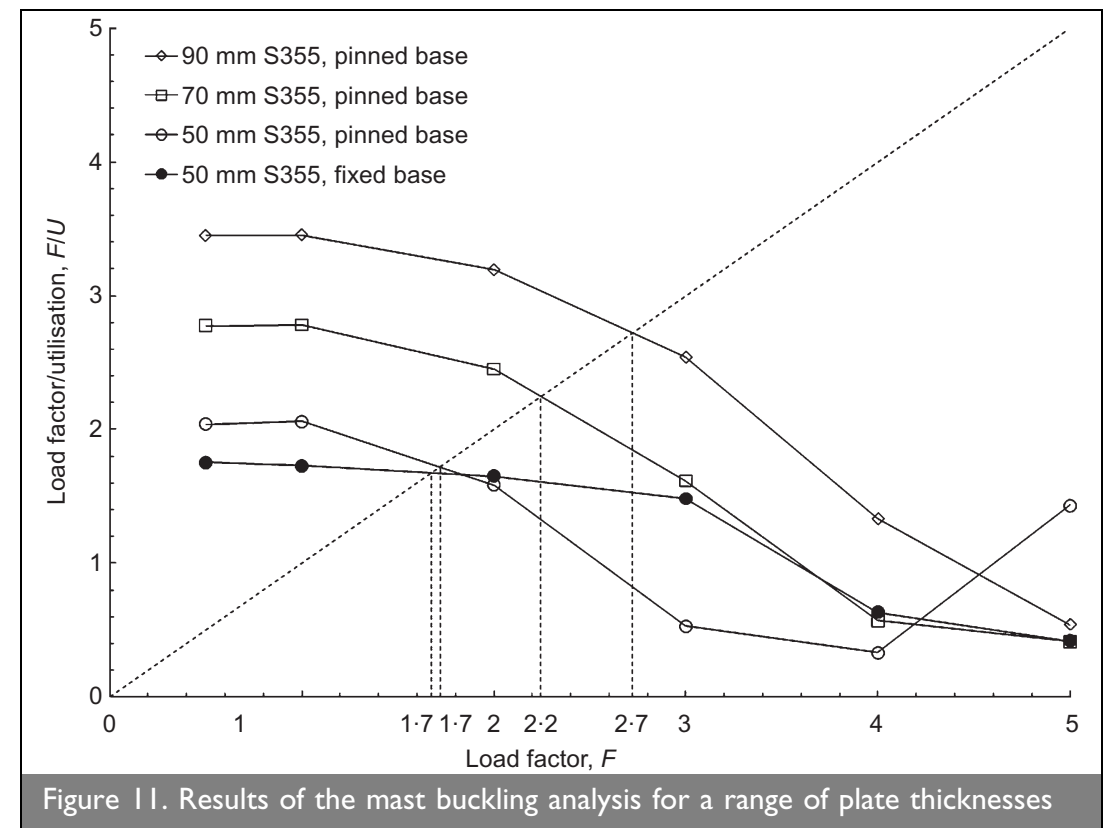

tolerance. However, studies indicated that the mast was relatively insensitive to the magnitude of the initial imperfection by virtue of its slenderness. The actual fabricated mast was surveyed and found to have a maximum initial bow of $15 \mathrm{~mm}$.

The back stays connect to a steel anchor plate stressed down on to the concrete substructure. A cast-in steel frame was provided to set the anchor bars in position accurately before concreting (see Figure 12). The frame was assembled in the fabrication shop where the complicated geometry could be accurately set and checked under controlled conditions. Subsequent setting of the frame on site was a relatively simple task. Whereas the cost of the frames was not insignificant, they saved a considerable amount of time on site and mitigated against the unfavourable consequences of misalignment in stays. The finished configuration is shown in Figure 13.

\section{CONSTRUCTION}

The bridge was specifically designed to minimise on-site work.
The completed $67 \mathrm{t}$ mast was transported by road in a single piece. The $104 \mathrm{t}$ spine beam was delivered in two sections and the deck in eight: four skewed end units and a further four internal units. In total, the pedestrian deck units weighed $57 \mathrm{t}$ and the vehicle deck units weighed $118 \mathrm{t}$.

After fabrication and before being transported to site by road, a full trial erection of the central spine beam and deck units was undertaken at the fabricator's works in Newport, South Wales. Temporary support trestles were provided in the central reservation and at the abutments to support the spine beam and deck units in the temporary condition. The bridge steelwork was installed in two road closures over successive weekends.

The first possession was used to install the spine beam in two sections, the mast and the four skewed deck units at the abutments, with the mast initially held by just two of the back stays. After butt welding the two spine beam sections together, the butt welds connecting the trimmer beams to the spine beam were made. At this stage sufficient torsional restraint was

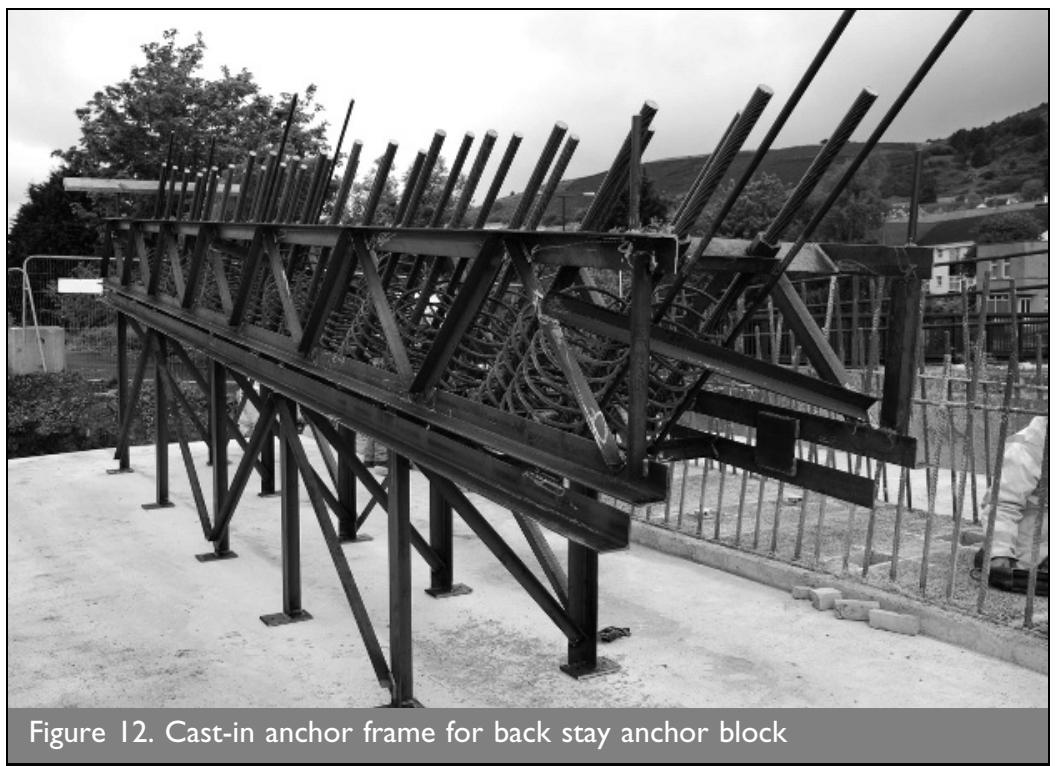




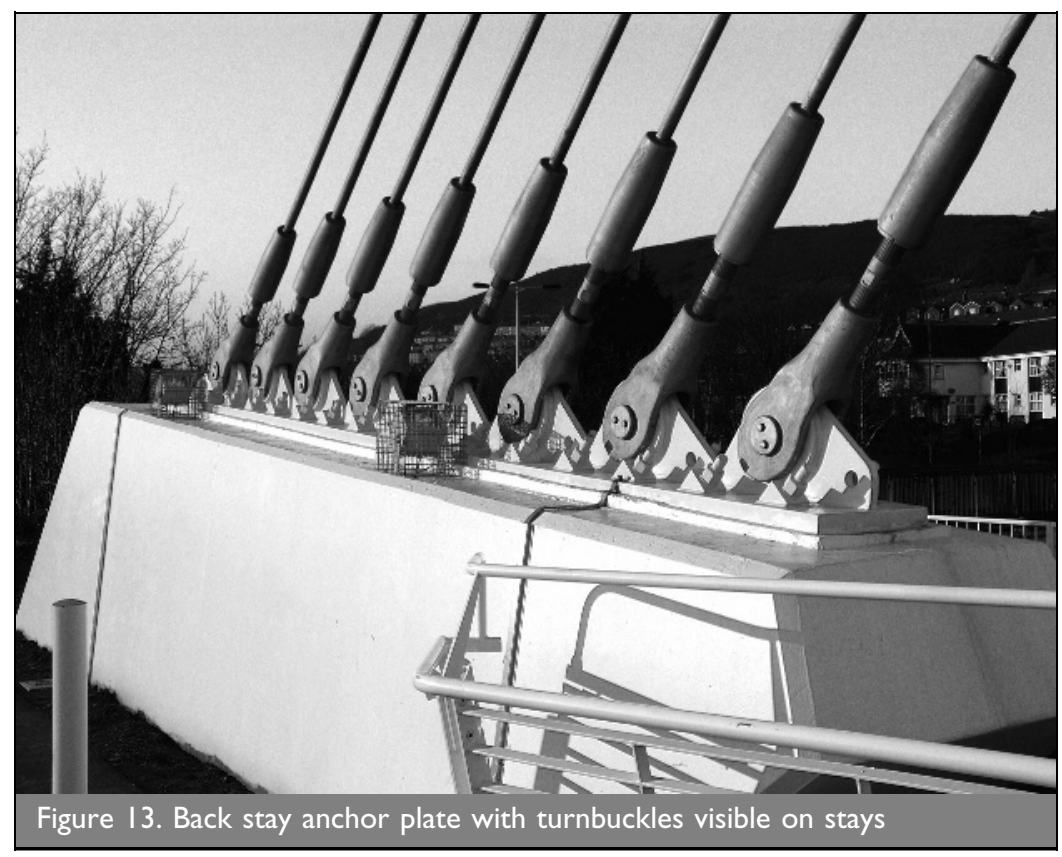

available to the spine beam to enable the remaining deck units to be bolted to the spine beam as part of the second possession. Figure 14 shows the position of the site splices in the deck panels.
These internal deck units, each up to $25 \mathrm{~m}$ in length, were delivered to site and suspended by chain blocks from a lightweight modular lifting beam during installation, see Figure 15. This innovative arrangement, proposed by the

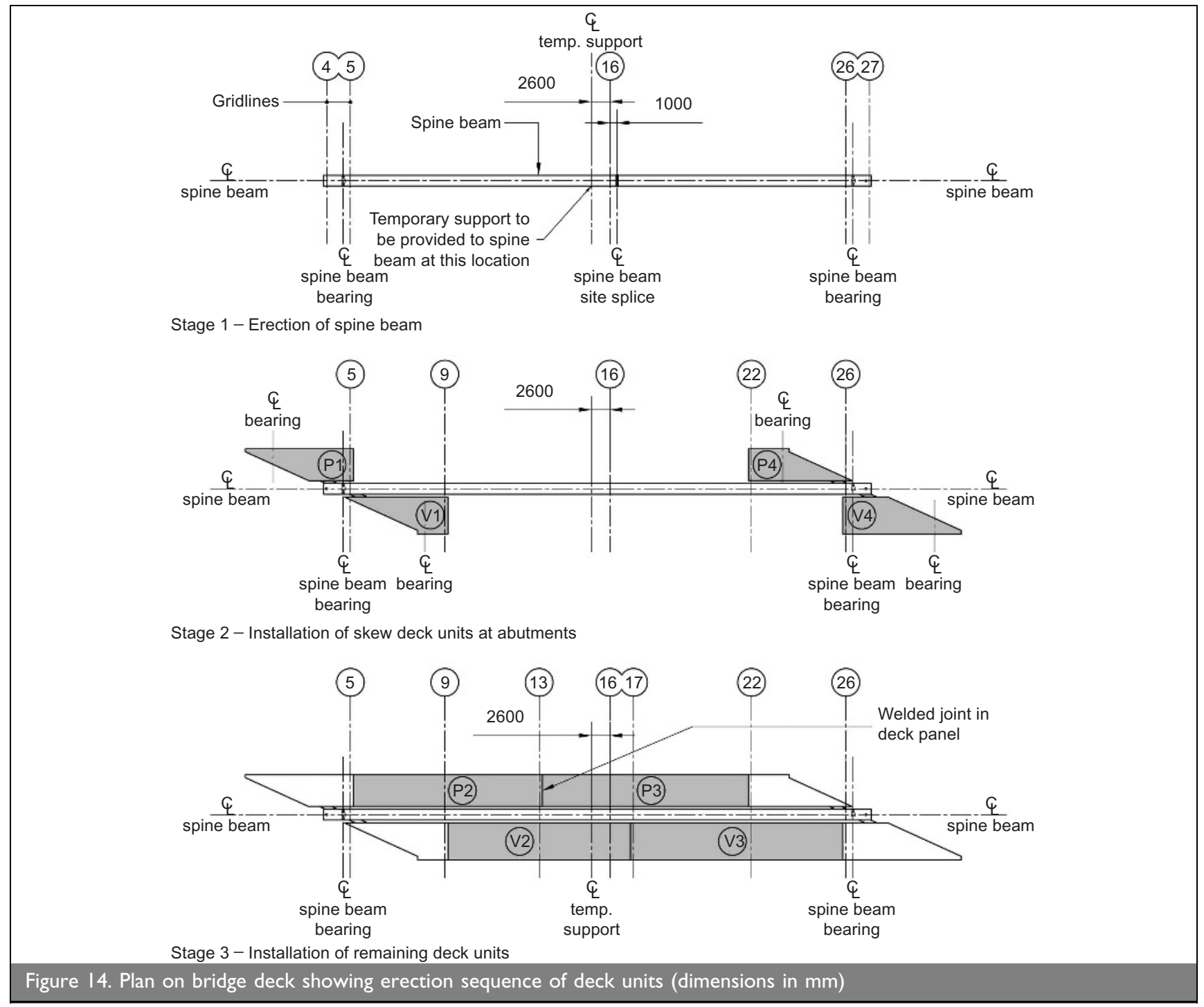




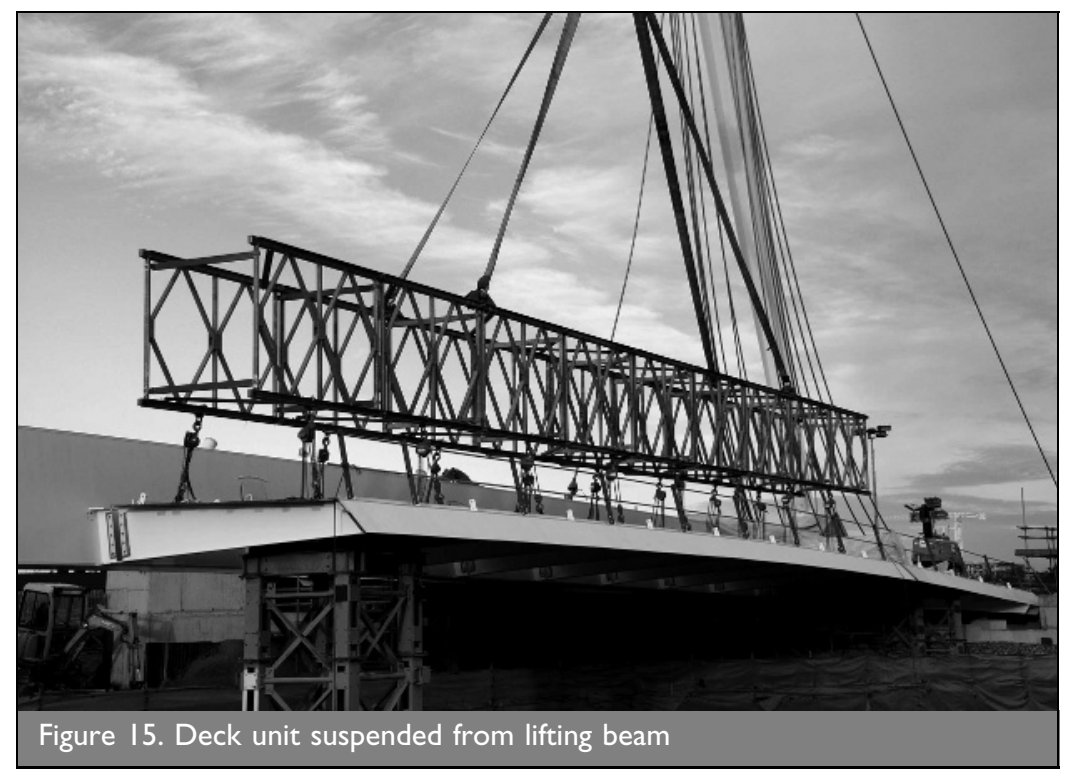

contractor, provided the ability to adjust the geometry of the relatively flexible deck units to match the geometry of the spine beam before completing the splice connections at the root of the cantilevers using high strength friction grip bolts.

Significant welding distortion occurred when the trimmer beams were welded to the spine beam, giving the potential to lock in additional restraint forces at the abutment bearings. Therefore, on completion of all welding, the bridge was set on jacks at the abutments and the correct permanent bearing forces established before grouting the bearings.

Under self-weight alone the asymmetric cross-section with its heavier vehicle deck resulted in a torsional displacement of the spine beam - an unusual precamber problem. Discussion with the fabricator confirmed Flint \& Neill's view that it was not practicable to fabricate the spine beam in an unstressed condition that would counteract this permanent twist. Therefore, in the theoretical unstressed state each cantilever cross-girder was preset in an upwards direction for the vehicle deck or a downwards direction for the pedestrian deck, as shown in Figure 16. In the finished condition the required geometry is obtained along the fascia beams, although there is an imperceptible permanent twist in the spine beam. It is worth noting that under the action of a typical fully laden bus the maximum cantilever tip deflection on the vehicle deck is approximately $65 \mathrm{~mm}$, whereas under full design loading the deflection is $265 \mathrm{~mm}$.

\section{STAY STRESSING}

The $56 \mathrm{~mm}$ diameter locked-coil stays were installed in accordance with a stay tensioning sequence developed to minimise the number of stressing increments required. The behaviour of the stays is near-linear as a result of their short length and low sag, thereby allowing a sequential series of global analytical models to be developed, each modelling the addition of an individual stay to the previous model. For each stay in every model, the effect of a unit change in stay preload was determined and the results combined in matrix form in a spreadsheet. Using this matrix, the effect of changing the preload in any given stay at any point in the stressing sequence could be determined with relative ease, and by means of linear programming, the optimum incremental stay jack loads and displacements could be calculated for each stage. In addition to helping develop an optimum stressing sequence, this tool proved to be an invaluable aid during construction, as the effect of variations in the planned stressing sequence could be rapidly ascertained by the designer on site. This provided flexibility and allowed real-time observations on site to be incorporated into the model, increasing the accuracy of final stay preloads and allowing a prompt and informed response when the target load was not achieved during the first stressing cycle. Each stay was stressed in just two increments. At the start of the second increment, the actual load in the stay could be measured and compared against the expected load. Extremely good agreement was achieved between theoretical and actual stay loads, with the final stay loads being within $10 \%$ of the intended load for all

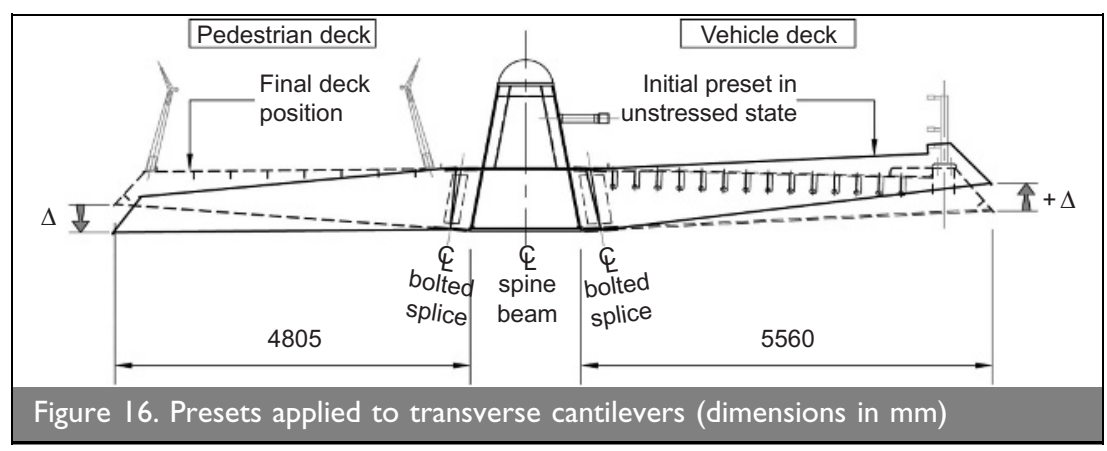




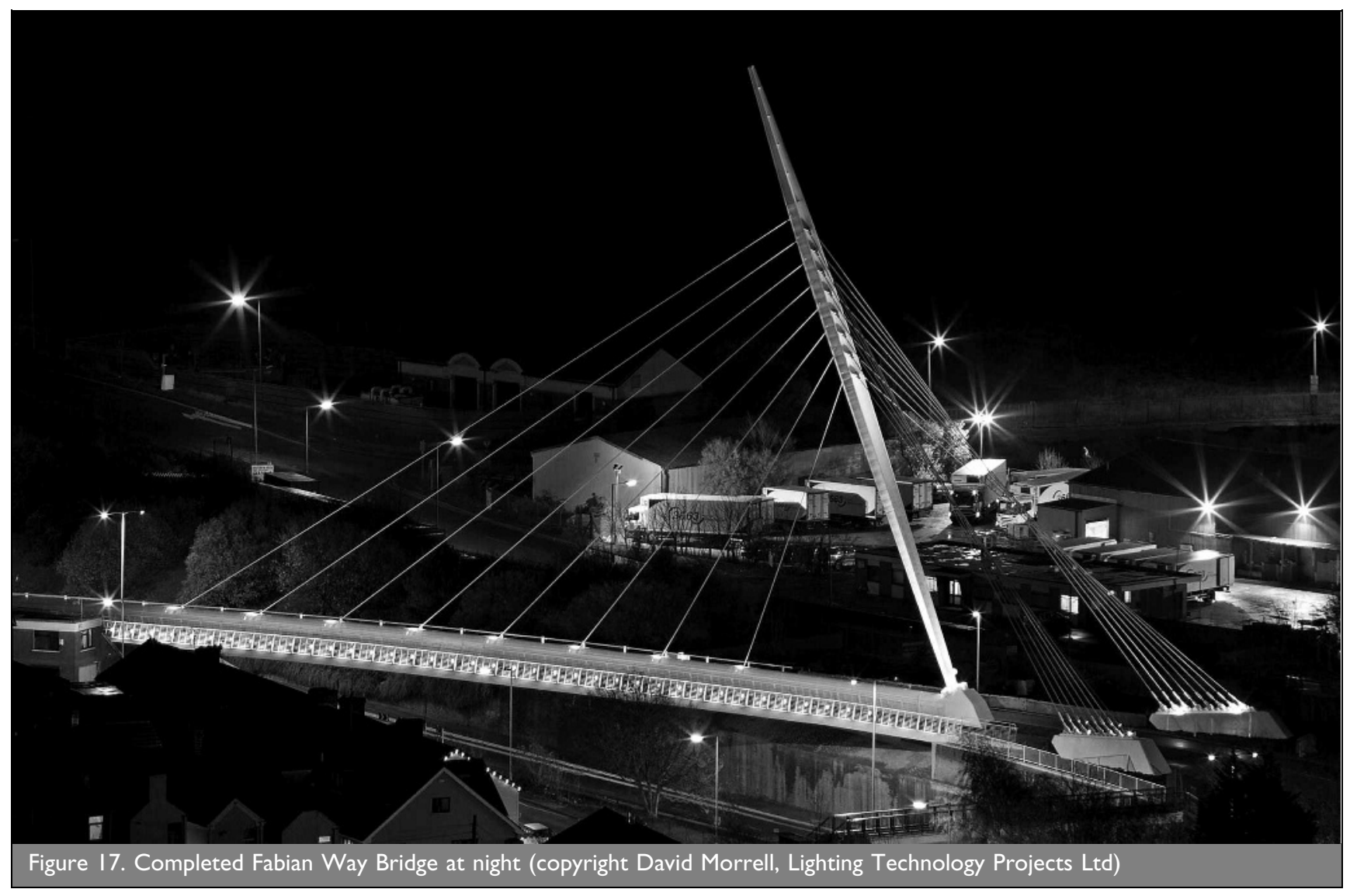

stays. It took approximately 10 days to complete stressing of the stays, although the majority of the time was spent dismantling, moving and re-assembling the jacking equipment.

Parapets and expansion joints were installed before final painting. The vehicle deck was surfaced with a $40 \mathrm{~mm}$ thick mastic asphalt system and a thin epoxy-based waterproofing and anti-skid system was applied to the pedestrian deck.

\section{CONCLUSIONS}

The Fabian Way Bridge has become a 'landmark' structure across one of the major arteries into the city of Swansea (see Figure 17). The bridge was designed and built in a relatively short period of time and demonstrates what can be achieved through effective collaboration between the designer and fabricator. The adoption of an alternative steel deck design maximised off-site prefabrication and minimised road closures and work above the live carriageway. The alternative deck design reduced the weight of the suspended structure and permitted significant improvements and economies to be made in the design of the mast, stays and foundations. The striking appearance of the bridge, in particular the slender mast, has been instrumental in the project's success.

\section{ACKNOWLEDGEMENTS}

The authors would like to acknowledge the role and vision of the client, City and Council of Swansea, in particular Brian Williams and Alun Thomas. The positive approach demonstrated by both the main contractor Alun Griffiths Ltd and steelwork specialist Rowecord Engineering Ltd was key to the success of the project.

\section{REFERENCES}

BSI (British Standards Institution) (1980) BS 5400-10: Steel, concrete and composite bridges - Part 10: Code of practice for fatigue. BSI, London.

BSI (1999) BS 5400-6: Steel, concrete and composite bridges Part 6: Specification for materials and workmanship, steel. BSI, London.

BSI (2000) BS 5400-3: Steel, concrete and composite bridges Part 3: Code of practice for design of steel bridges. BSI, London.

BSI (2006) Eurocode 3 - Design of steel structures - Part 2: Steel bridges. BSI, London. BS EN 1993-2.

Sanders PA and Firth IPT (2005) The design and construction of the Sail Bridge, Swansea. Proceedings of the Institution of Civil Engineers, Bridge Engineering 158(4): 143-153.

\section{What do you think?}

To discuss this paper, please email up to 500 words to the editor at journals@ice.org.uk. Your contribution will be forwarded to the author(s) for a reply and, if considered appropriate by the editorial panel, will be published as discussion in a future issue of the journal.

Proceedings journals rely entirely on contributions sent in by civil engineering professionals, academics and students. Papers should be 2000-5000 words long (briefing papers should be 1000-2000 words long), with adequate illustrations and references. You can submit your paper online via www.icevirtuallibrary.com/content/journals, where you will also find detailed author guidelines. 